\title{
¿Qué significa ser revolucionario, aquí y ahora, o acaso esto ya es cosa del pasado?
}

Recientemente cierta amiga me susurró al oído: "Dígame, ¿qué significa ser de izquierda ahora?". En realidad, pareciera que ser de izquierda y ser revolucionario es lo mismo. Pero no. Ni es lo mismo, ni es igual. De izquierda se puede ser con un mínimo de esfuerzo. Ser de izquierda es más como un "look" pequeño burgués, un estar en la onda, en la moda. No es más de lo que fue la onda hippie por estos lares: con pelo largo, ropa de manta, Queen en los oídos, presumir de ateo, gritar: "Yanki go home", leer a Benedetti y pasársela bebiendo en los bebederos de mala muerte que habían por la Praviana. $\mathrm{O}$ como ahora que los chavos y chavas disque de izquierda, que han descubierto la bohemia, le hacen al monte, imitan a Roque y se la pasan en los cafés de izquierda renegando, añorando, llorando y hasta maldiciendo a los "facundos". Ser de izquierda no es lo mismo que ser de oposición, pero es igual, como dicen que dijo el poeta cantor.

Por todo ello es que preferimos preguntarnos por las implicaciones y el significado de ser revolucionario. Además, porque como me dijo otro amigo: "Ser de izquierda suena europeo". El Che fue revolucionario. A nadie se le ocurriría decir que fue de izquierda. Se entiende lo de nadie, ¿verdad?

La pregunta primera con la que iniciamos este escrito tiene sus trampas: los adverbios de lugar y tiempo insinúan algo. Una respuesta rápida y despistada podría sostener que, ser revolucionario, aquí y ahora, ya no significa nada, porque la revolución es ya cosa del pasado, luego de los acuer- dos de paz del 92 que pusieron fin a la guerra "revolucionaria". Pero, ¿ es que acaso la guerra fue revolucionaria? Digamos que participaron en ella muchos que eran revolucionarios, que peleaban por una revolución socialista, pero la lucha se quedó inconclusa - sin victoria y sin derrota- y resulta imposible calificar de revolucionaria a la guerra, porque para serlo debió haber dado lugar a una sociedad radicalmente nueva, lo cual no ha sucedido. Pero que no quepa duda alguna, que si los jóvenes de entonces ofrecieron sus vidas sin miseria, no fue por cierto para que algunos ex guerrilleros vivieran como pequeño-burgueses ahora, gracias a los emolumentos que reciben en la Asamblea.

La segunda parte de la pregunta es igual de insinuante, al recoger esa sospechosa y muy generalizada opinión de que en El Salvador de hoy no hay lugar para planteamientos confrontativos, mucho menos para propuestas y acciones revolucionarias. Hablar de revolución es algo que no se puede hacer y además no se debe hacer, porque "al hacerlo se le dan armas al enemigo". Hubo un tiempo en que los comandantes de la guerrilla le salían al paso a cualquier cuestionamiento que se les hacía, con argumentos de ese tipo: "darle armas al enemigo" era el bozal que amordazaba cualquier opinión diferente. Con dogmas como ese escondieron toda la ignorancia que ahora exhiben públicamente, con el más desfachatado cinismo y con el mayor irrespeto a nuestra inteligencia.

Pues bien, ser revolucionario aquí y ahora sigue teniendo la misma exigencia que tuvo en la 
década pasada. El que algunos pseudorrevolucionarios hubiesen claudicado ante los favores del sistema no cambia para nada las cosas. De la desmovilización armada no se sigue: desmovilización de las ideas. Para las mayorías populares que abonaron con su sangre la esperanza, ésta no puede verse terminada con unos acuerdos de paz que no transformaron en nada el sistema socioeconómico, causa y razón de la injusticia, de la lucha, de la revolución pospuesta.

Los herederos de Farabundo, ciertamente, no pueden ser esos que confundieron el rojo de la sangre derramada por tantos héroes y mártires, con el vulgar rojo de la expulsión futbolística. Ser revolucionario sigue implicando lo mismo: batallar incansablemente, luchar hasta el fin por la construcción de una nueva forma de organización social que sea superior en todo y por todo a la civilización del capital. Esta nueva sociedad a la que, por oposición a la del capital, se le denomina civilización del trabajo, deberá hacer posible la realización plena de los seres humanos. Ya que resulta un escándalo que al haber alcanzado la humanidad el mayor desarrollo científico y tecnológico, el contar con las mayores riquezas materiales, haber visitado la Luna, explorado Marte y otros planetas, aún se mueran de hambre millones de humanos. La miseria, la desgracia, la peste siguen siendo el mal generalizado de los pobres y los otros, los que nacieron en el primer mundo, se suicidan o no quieren reproducirse. Sábato nos dice: "Así como los animales en cautiverio, nuestras jóvenes generaciones no se arriesgan a ser padres. Tal es el estado del mundo que les estamos entregando".

Si por un momento nos ponemos serios y observamos la realidad demencial que nos rodea. $\mathrm{Si}$ por un momento no hacemos caso a las justificaciones ni a las explicaciones mentirosas de los prendados del sistema; si por un momento, si tan sólo por un momento recobramos la cordura de los años frescos con olor a vida, se nos dibujará, sin duda, nuevamente en toda su nitidez la sociedad futura y la fuerza de su utopía nos impulsará de nuevo hacia la acción: al batallar decidido y franco. Seguro que nuevas formas de lucha se harán presentes, ya que la creatividad de los pueblos no

tiene límites cuando de trabajar se trata por la liberación definitiva.

Ser revolucionario significa también, aunque parezca poca cosa, revolucionar nuestra forma cotidiana de vida. Liberarnos de las dependencias, de los malos hábitos, de todos los vicios del sistema. ¿Cómo podríamos aspirar a ser revolucionarios si practicamos el consumismo tan propio del sistema? ¿O si el individualismo y el egoísmo rigen nuestras vidas? Ciertamente no se trata de odiar a quienes son presas o víctimas del sistema, pero al menos creo que nos es dado despreciar a quienes se venden al mejor postor en un afán demencial por tener y tener más y más bienes materiales, creyendo estúpidamente que el tener es más importante que el ser.

El ser revolucionario implica vivir con nuevos valores 0 , en todo caso, con valores muy distintos de aquellos que buscan introyectar el capitalismo. Ciertamente no se trata de enajenarse a la colectividad, sino de realizar la individualidad propia en la comunidad, porque es comunidad de intereses, de ideas, de sueños, de fortalezas. Todo lo cual induce a la cooperación, solidaridad y unidad.

Ser revolucionario, obviamente, significa ser anti-sistema, más no anti-sistema porque sí, sino porque habiéndonos enardecido y conmovido ante la miseria, la injusticia, la explotación y tantos otros males propios del sistema capitalista, llegamos a la comprobación teórico-científica de que es imposible que éstos sean eliminados del sistema, porque éste se fundamenta en ellos. 
Pretender que el capitalismo no presenta clases sociales antagónicas o que la burguesía no explota a los trabajadores asalariados, sencillamente es un sin sentido, porque el sistema se fundamenta en la explotación del trabajo asalariado, si no hubiera asalariados a quienes explotar no existiría capitalismo.

Igual de absurdo resulta pretender que los empresarios capitalistas renuncien a sus beneficios. Hacerlo implicaría renunciar a su propia naturaleza social, razón por la cual se presenta una férrea oposición entre beneficios y salarios. Y los empresarios estarían dispuestos a cualquier cosa, antes que sacrificar sus beneficios para aumentar salarios.

Igual de poco inteligente resulta también el pedirle a los empresarios de un determinado país que generen empleo, si al hacerlo lejos de obtener beneficios, tan sólo dilapidan dinero en salarios. Los capitalistas cuando ven sus intereses amenazados, ciertamente, alegan que de cerrar sus negocios se perderían cantidad de puestos de trabajo, lo cual no es falso, pero no es menos cierto que si generan empleo es porque al hacerlo obtienen beneficios. Y esto, y no el dar ocupación a las personas, es lo que los anima a invertir su dinero.

Mientras el capital se siga valorizando, poco importa la magnitud de la miseria mundial o la cantidad de empresas capitalistas que haya que quebrar, o los cientos de miles de trabajadores que haya que lanzar a la calle cuando se dan las fusiones entre empresas o las nuevas tecnologías los hacen innecesarios.

Por eso es que mientras las cosas le marchen bien al capital, los empresarios claman por más y más mercado libre; sólo cuando las ganancias declinan, los empresarios se acuerdan de que el Estado burgués está para protegerlos, aunque las acciones gubernamentales se justifiquen alegando que es para evitar que los trabajadores queden cesantes.

El sistema capitalista, como cualquier sistema social, está regido por leyes, las cuales es preciso que conozca quien aspira a ser revolucionario a profundidad, ya que sólo así podrá comprender al sistema y conocerá cuales son sus posibles tendencias. A esto le dedicó mucho tiempo y energía Carlos Marx, y aunque sobra más de algún ignorante que opine que la teoría marxista ya está obsoleta, lo único que hacen es caer en posiciones pre-marxistas, con lo cual se niegan la posibilidad de comprender a profundidad el sistema capitalista: sus ventajas y desventajas, sus contradicciones, tendencias y fundamentos. Pues bien, entre los muchos aportes de Marx está la "Ley General de Acumulación del capital", la cual nos plantea que mientras por una parte se acumula riqueza en manos de unos cuantos capitalistas, por otra se generaliza la pobreza para la mayoría de las personas. Pretender que ésta no es la realidad mundial actual capitalista es tan poco serio como pretender tapar el sol con un dedo.

En línea con lo anterior tenemos que el capitalismo tiende inexorablemente hacia la concentración y centralización del capital, lo cual se traduce en oligopolios o monopolios. Esta realidad, desarrollada teóricamente por Marx el siglo pasado, presenta una inobjetable realidad en nuestros tiempos que el pretender negarla resulta tan necio, como la pretensión de impedir la proliferación de monopolios u oligopolios con base en preceptos jurídicos, o cuando menos revela la ingenuidad o ignorancia de los legisladores que proponen tales normas, quienes presuntamente son de izquierda pero no revolucionarios, obviamente.

Por otra parte, debemos señalar que en los países capitalistas subdesarrollados, como es el caso del nuestro, el capital, para compensar muchas de sus desventajas provenientes del bajo desarrollo de las fuerzas productivas $y$ aprovechando la existencia de formas de producción y circulación no capitalistas, muy propias del subdesarrollo, acude a la sobreexplotación de la fuerza de trabajo asalariada y a la expoliación de los trabajadores no asalariados, razón por la cual obtiene tasas de ganancia muy elevadas. Siendo esto así, creer que somos países en vías de desarrollo, o esperar que el desarrollo provendrá de los sectores empresariales capitalistas, sencillamente es no entender cómo es la realidad de las cosas en el capitalismo del tercer mundo. Hablamos de desarrollo en su correcto sentido y no como simple crecimiento económico o modernización, los cuales son muy propios del capitalismo, sin que se traduzcan en bienestar social para las grandes mayorías.

Igualmente es importante entender que si bien las sociedades capitalistas son inmensos arsenales de mercaderías, tanto materiales como inmateriales, si no se tiene poder de compra es posible morir de hambre o de la más corriente de las enfermedades, esto, obviamente, no ocurre en socieda- 
des no capitalistas, como lo están descubriendo tardíamente, aunque por razones distintas, tanto los indígenas del Amazonas como los habitantes de la ex Unión Soviética.

Para finalizar, deseamos decir que la lucha revolucionaria no tiene porqué identificarse con la lucha armada, como tampoco la lucha revolucionaria justifica comportamientos inhumanos, mucho menos acciones criminales. El auténtico revolucionario sabe que los capitalistas son tan sólo la personificación del capital y que ellos, en tanto que personas, tienen derechos humanos que es preciso respetar. El revolucionario busca vida para todos aquellos a quienes el sistema se las niega y, en consecuencia, nunca podrá estar contra la vida de nadie.

El ser revolucionario, verdadero revolucionario, no tiene porque ser necesariamente identificable con el ser guerrillero... Demasiada muerte y dolor ocasionó la guerra en nuestro país como para estar a favor de esa descalificada forma de lucha. Las acciones criminales del enemigo no pueden legitimar ni justificar acciones criminales del revolucionario, sólo así es posible engendrar al hombre y la mujer nuevos que la revolución necesita.

Aquiles Montoya

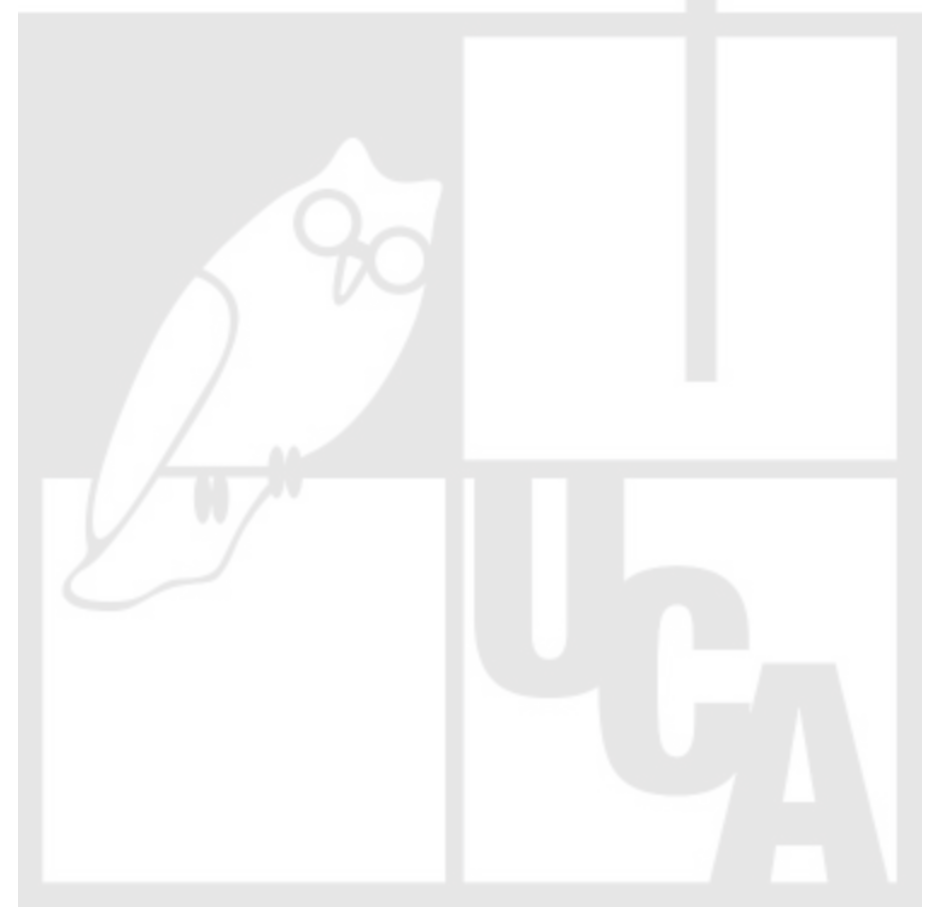

